Note

\title{
Effect of Renal Denervation on Phosphate Excretion in Endotoxemic Rats
}

\author{
NAOKI HIKI AND YOSHIKAZU MIMURA \\ Endocrine Unit, Third Department of Surgery, University of Tokyo, Tokyo 112, Japan
}

\begin{abstract}
Our previous studies showed that endotoxin (Et) administration causes hypophosphaturia in the presence of PTH. In this study, we tested the hypothesis that enhanced renal nerve activity during endotoxemia is responsible for hypophosphaturia. Two weeks after bilateral renal denervation, phosphate excretion was examined in endotoxemic Wistar rats ( $300 \mathrm{~g}$ body weight). Renal clearance studies were performed before and after $4 \mathrm{mg} / \mathrm{kg}$ body weight Escherichia coli Et administration. Et administration resulted in a marked fall in glomerular filtration rates of innervated rats $(n=12$, from 2.09 $\pm 0.11 \mathrm{ml} / \mathrm{min}$ to $0.89 \pm 0.15 \mathrm{ml} / \mathrm{min}, P<0.005)$ compared to saline-treated innervated rats $(\mathrm{n}=7$, from 1.98 $\pm 0.19 \mathrm{ml} / \mathrm{min}$ to $1.76 \pm 0.16 \mathrm{ml} / \mathrm{min}$ ). The glomerular filtration rate of renal denervated rats was the same for saline-treated rats $(\mathrm{n}=9$, from $2.67 \pm 0.92 \mathrm{ml} / \mathrm{min}$ to $1.69 \pm 0.12 \mathrm{ml} / \mathrm{min})$ and Et-treated rats $(\mathrm{n}=10$, from $2.37 \pm 0.19 \mathrm{ml} / \mathrm{min}$ to $1.52 \pm 0.07 \mathrm{ml} / \mathrm{min}$ ). Fractional phosphate excretion was significantly reduced after Et challenge in innervated rats (from $24.0 \pm 3.3 \%$ to $11.8 \pm 2.2 \%, P<0.0001$ ) compared to saline injection in innervated rats (from $26.9 \pm 3.9 \%$ to $33.0 \pm 1.6 \%$ ). Although renal denervation improved the hypophosphaturia in comparison to the innervated rats, fractional phosphate excretion was still lower in Et-treated rats (from $28.8 \pm 5.0 \%$ to $18.0 \pm 4.7 \%, P<0.005$ ) than in saline-treated rats (from $30.2 \pm 6.1 \%$ to $38.7 \pm 4.2 \%$ ). In conclusion, our data did not support the hypothesis that renal nerves have an important role in reducing renal phosphate excretion during acute endotoxemia.
\end{abstract}

Key words: Endotoxemia, PTH, Phosphate excretion, Renal denervation

(Endocrine Journal 44: 739-744, 1997)

PHOSPHATE is an essential element for energy producing [1-3] and oxygen delivery systems [4, 5]. The role of phosphate may increase during surgical stress, such as severely infectious and oxygen depleted conditions where energy requirements markedly increase to meet the enhanced energy demand for protein synthesis [6]. Phosphate homeostasis is maintained by controlling renal phosphate excretion which is mainly controlled by PTH, but little information is available about phosphate excretion during endotoxemia $[7,8]$. In particular, there is no precise

Received: December 20, 1996

Accepted: July 8, 1997

Correspondence to: Dr. Yoshikazu MIMURA, Third Department of Surgery, University of Tokyo, 3-28-6 Mejirodai, Bunkyo-ku, Toky 112, Japan information about PTH activity in severe infection.

In our previous studies, the renal response to endotoxin (Et) administration was found to be resistant to the phosphaturic effect of PTH [7]; hormonal and blood neutrality alterations, such as an increased norepinephrine excretion, hypocapnia, and metabolic acidosis were observed in these previous studies, and all of these responses inhibit the phosphaturic effect of PTH [9-14], in particular the first two factors do it by enhancing renal nerve activity. We, therefore, hypothesized that enhanced renal nerve activity during endotoxemia is responsible for the observed hypophosphaturia. The present study was designed to investigate phosphate excretion after Et administration in renal denervated rats to determine whether renal nerves serve to increase phosphate excretion during acute endotoxemia. 


\section{Methods}

The animals used in the present study were treated in accordance with the guidelines laid down for the care of laboratory animals by the authors' institution. Male Wistar rats (Tokyo Jikken Dobutsu, Tokyo) underwent bilateral renal denervation (DNX) 14 days prior to the acute experiment. Both kidneys were denervated by stripping the renal artery and vein of adventitia and connective tissue and cutting all visible nerves to the kidneys. Then the renal artery and vein were painted with $10 \%$ phenol in ethanol [15]. Rats that underwent sham operations served as control rats with innervated (INN) kidneys. After these surgical procedures, all the rats were fed the normal rat chow containing normal $\mathrm{Pi}(1.11 \%)$, calcium (1.16\%) and vitamin D (2 IU/g chow).

On the day of the acute experiment rats, weighing $300 \mathrm{~g}$ were anesthetized by an intraperitoneal injection of $5 \mathrm{mg} / 100 \mathrm{~g}$ body weight (wt) sodium pentobarbital (Nembutal, Abbott Laboratories, North Chicago, IL). They were placed on a heated table throughout the experiment. A Silascon catheter (ID $0.5 \mathrm{~mm}$, OD $1.0 \mathrm{~mm}$, Kaneka Medex, Kanagawa) was placed in the right jugular vein for infusions and a polyethylene catheter (ID $0.5 \mathrm{~mm}$, OD $1.0 \mathrm{~mm}$, Natsume Seisakusho, Tokyo) was placed in the left carotid artery for blood sampling and blood pressure monitoring. A polyethylene catheter (ID $1.2 \mathrm{~mm}$, OD $1.7 \mathrm{~mm}$ ) was placed in the urinary bladder for urine collection. A tracheostomy was performed and a polyethylene catheter (ID $1.5 \mathrm{~mm}$, OD $2.7 \mathrm{~mm}$ ) was placed in the trachea. A solution of $3 \%$ inulin in $0.9 \%$ saline was infused at a rate of $1.5 \mathrm{ml} / \mathrm{h}$ throughout the experiment. Infusion of $6.25 \%$ albumin (bovine albumin, Sigma Chemical, St. Louis, MO) in lactate Ringer solution was begun at a rate of $3 \%$ body $\mathrm{wt} / \mathrm{h}$ after the surgical procedures and $30 \mathrm{~min}$ later was decreased to $2 \%$ body wt/h. After a $60-\mathrm{min}$ period of recovery from the catheterization operation, a 30-min control urine sample was taken. Blood samples were withdrawn for serum inulin and electrolyte measurements, and arterial blood gas analysis at the end of the 30-min clearance period. Escherichia. coli Et (055: B5, Difco Laboratories, Detroit, MI) was then injected intravenously as a bolus dose of $4 \mathrm{mg} / \mathrm{kg}$. The rats were randomly divided into the following four groups.

Group 1: DNX + Et $(\mathrm{n}=10)$. One hundred and twenty min after an injection of Et, a 30-min experimental clearance test was started.

Group 2: INN + Et $(n=12)$. The protocol was the same as that for group 1, except that the renal nerves were intact.

Groups $3(\mathrm{n}=9)$ and $4(\mathrm{n}=7)$. The protocols for these groups of rats were exactly the same as for groups 1 and 2, except that saline vehicle was administered instead of Et.

\section{Analytical techniques}

Serum samples were obtained by centrifugation of blood samples at $4{ }^{\circ} \mathrm{C}$, and aliquots for each assay were stored at $-70^{\circ} \mathrm{C}$ until all the samples had been collected. Arterial blood gas analysis was performed on an ABL-2 (Radiometer Corp., Copenhagen). The glomerular filtration rate (GFR) was calculated by using the inulin clearance data. Serum and urinary inulin concentrations were measured by the anthrone method [16]. Serum and urinary concentrations of sodium were determined by an electrolysis method, phosphate by an enzyme assay method and calcium by the oCPC technique with an automatic analyzer (Hitachi 736: Hitachi Co. Ltd, Tokyo).

All values shown are the means \pm SEM. Comparisons between control and Et administration periods within a group were made by paired $t$ test. Two-way ANOVA was used to compare Etand saline-treated rats in the presence and absence of renal nerves. $P<0.05$ was accepted as a statistically significant difference.

\section{Results}

Table 1 summarizes the renal function and phosphate excretion data for INN and DNX rats during endotoxemia. Mean arterial pressures were stable throughout the experiment except for the INN endotoxemic rats which had higher basal values than those for the saline-treated rats that fell noticeably after Et challenge. There were no differences between Et- and saline-treated rats in basal GFR values. The GFR of INN rats after Et administration was significantly lower than the basal rate, and was also significantly lower than that of saline-injected rats. Although the GFR after 
Table 1. Effect of renal denervation on phosphate excretion in endotoxemic rats

\begin{tabular}{|c|c|c|c|c|c|c|c|c|c|c|c|c|}
\hline & \multicolumn{4}{|c|}{ Et-treated } & \multicolumn{4}{|c|}{ Saline-treated } & \multicolumn{4}{|c|}{$P$ values (two-way ANOVA) } \\
\hline & \multicolumn{2}{|c|}{ DNX (10) } & \multicolumn{2}{|c|}{ INN (12) } & \multicolumn{2}{|c|}{ DNX (9) } & \multicolumn{2}{|c|}{ INN (7) } & \multicolumn{2}{|c|}{$\mathrm{C}$} & \multicolumn{2}{|c|}{ Et/Saline } \\
\hline & C & Et & $\mathrm{C}$ & Et & C & Saline & C & Saline & $\begin{array}{l}\text { Treat- } \\
\text { ment }\end{array}$ & $\begin{array}{l}\text { Renal } \\
\text { nerves }\end{array}$ & $\begin{array}{l}\text { Treat- } \\
\text { ment }\end{array}$ & $\begin{array}{l}\text { Renal } \\
\text { nerves }\end{array}$ \\
\hline MAP (mmHg) & $116 \pm 4$ & $113 \pm 4$ & $119 \pm 2$ & $105 \pm 3^{\S}$ & $111 \pm 5$ & $111 \pm 5$ & $108 \pm 4$ & $107 \pm 5$ & 0.0343 & 0.9245 & 0.9861 & 0.1816 \\
\hline $\mathrm{GFR}(\mathrm{ml} / \mathrm{ml})$ & $2.37 \pm 0.19$ & $1.52 \pm 0.07^{\S}$ & $\S_{2.09 \pm 0.11}$ & $0.89 \pm 0.15^{\S}$ & $\S 2.67 \pm 0.92$ & $1.69 \pm 0.12$ & $1.98 \pm 0.19$ & $1.76 \pm 0.16^{\S}$ & 0.8423 & 0.3206 & 0.0004 & 0.0413 \\
\hline $\mathrm{V}(\mu l / \min )$ & $142 \pm 18$ & $56 \pm 8^{\S}$ & $146 \pm 14$ & $22 \pm 4^{\S}$ & $127 \pm 19$ & $127 \pm 16$ & $113 \pm 22$ & $160 \pm 30$ & 0.2032 & 0.7774 & 0.0001 & 0.9821 \\
\hline $\mathrm{U}_{\mathrm{Na}} \mathrm{V}(\mu \mathrm{Eq} / \mathrm{min})$ & $15.8 \pm 1.7$ & $5.2 \pm 0.6^{\S}$ & $16.7 \pm 1.8$ & $2.5 \pm 0.6^{\S}$ & $15.5 \pm 1.6$ & $15.4 \pm 1.8$ & $17.0 \pm 3.0$ & $21.5 \pm 3.4$ & 0.9870 & 0.5618 & 0.0001 & 0.3095 \\
\hline $\mathrm{FE}_{\mathrm{Na}}(\%)$ & $5.15 \pm 0.61$ & $2.62 \pm 0.46^{\S}$ & $5.95 \pm 0.58$ & $3.58 \pm 1.16^{\S}$ & $\S 6.54 \pm 0.94$ & $6.42 \pm 0.73$ & $6.10 \pm 1.02$ & $8.48 \pm 0.91$ & 0.0920 & 0.5804 & 0.0001 & 0.2669 \\
\hline $\mathrm{s}-\mathrm{Pi}(\mathrm{mg} / \mathrm{d} l)$ & $6.3 \pm 0.2$ & $6.3 \pm 0.4$ & $6.4 \pm 0.2$ & $6.8 \pm 0.2$ & $5.9 \pm 0.2$ & $6.0 \pm 0.2$ & $6.0 \pm 0.2$ & $6.3 \pm 0.3$ & 0.1175 & 0.6001 & 0.1744 & 0.1577 \\
\hline $\mathrm{U}_{\mathrm{Pi}} \mathrm{V}(\mu \mathrm{g} / \mathrm{min})$ & $37.8 \pm 4.8$ & $16.7 \pm 4.1^{\S}$ & $31.6 \pm 4.4$ & $5.9 \pm 1.1^{\S}$ & $31.0 \pm 4.0$ & $37.2 \pm 2.6$ & $33.7 \pm 6.1$ & $36.3 \pm 3.5$ & 0.6399 & 0.7240 & 0.0001 & 0.0536 \\
\hline $\mathrm{FE}_{\mathrm{Pi}}(\%)$ & $28.8 \pm 5.0$ & $18.0 \pm 4.7 \S$ & $24.0 \pm 3.3$ & $11.8 \pm 2.2^{\S}$ & $30.2 \pm 6.1$ & $38.7 \pm 4.2$ & $26.9 \pm 3.9$ & $33.0 \pm 1.6$ & 0.6519 & 0.3980 & 0.0001 & 0.1070 \\
\hline $\operatorname{Reab}_{P_{i}} / \operatorname{Fil}_{P_{\mathrm{P}}}(\%)$ & $71.0 \pm 5.6$ & $82.2 \pm 5.4^{\S}$ & $76.0 \pm 3.3$ & $88.2 \pm 2.2^{\S}$ & $69.8 \pm 6.1$ & $61.2 \pm 4.2$ & $73.1 \pm 3.9$ & $67.0 \pm 1.6$ & 0.6749 & 0.4022 & 0.0001 & 0.1281 \\
\hline
\end{tabular}

All values are the means \pm SEM. Numbers in parentheses are the numbers of animals used. Et-treated, endotoxin-injected rats; Saline-treated, saline-injected rats; DNX, rats with denervated kidneys; INN, rats with innervated kidneys; C, control clearance period; Et, clearance period after endotoxin challenge; Saline, clearance period after saline treatment; MAP, mean arterial pressure; GFR, glomerular filtration rate; $\mathrm{V}$, urine flow rate; $\mathrm{U}_{\mathrm{Na}} \mathrm{V}$; urinary excretion of sodium; $\mathrm{FE}_{\mathrm{Na}}$, fractional excretion of sodium; s-Pi, serum concentration of phosphate; $\mathrm{U}_{\mathrm{Pi}} \mathrm{V}$; urinary excretion of phosphate; $\mathrm{FE}_{\mathrm{Pi}}$, fractional excretion of phosphate; $\mathrm{Reab}_{\mathrm{Pi}} / \mathrm{Fil}_{\mathrm{Pi}}$, ratio of reabsorption to filtered load of phosphate. Treatment, treatment effect of Et or saline injection; Renal nerves, renal nerve effect of DNX or INN; ${ }^{\S}$ significantly different from the control clearance period values, $P<0.05$, paired $t$-test.

Et injection in DNX rats was noticeably reduced from the basal value, it was significantly higher than in INN rats and was the same level as the GFRs of the saline-treated rats. Et administration caused oliguria and hyponatriuresis in INN rats compared to saline administration. After Et administration, mean values for urine flow rates and urinary sodium excretion in DNX rats were greater than those in INN rats, but not significantly different. Similarly, urinary phosphate excretion was noticeably reduced after Et administration in INN rats as compared with saline-treated rats. Renal DNX tended to increase the reduced phosphate excretion after Et treatment, but failed to restore it to the level seen in saline-treated rats. The hypophosphaturia in endotoxemic rats was due to significantly increased phosphate absorption as compared to saline-treated rats.

Table 2 shows the arterial blood gas analyses for all rats. Et administration produced significant decreases in both the arterial partial pressure of $\mathrm{CO}_{2}$ and bicarbonate ion concentrations compared to saline administration. Consequently, negative arterial base excess values were found in Et-treated rats as compared with positive values in salinetreated rats. Respiratory alkalosis was elicited in endotoxemic rats.

\section{Discussion}

In our previous studies, Et administration inhibited PTH-mediated phosphaturia in thyroparathyroidectomized rats [7]. In fact, the INN rats in the present study, which had intact parathyroid glands, showed signs of hypophosphaturia after Et injection. The endotoxemic DNX rats showed a greater increase in phosphate excretion than the INN rats, but failed to increase phosphate excretion to the level of saline-treated rats. Intense stimulation of renal nerves $[17,18]$ and hypocapnia $[19,20]$ are common neurohormonal and acid-base findings in endotoxemia and affect renal phosphate excretion. Alpha-adrenergic stimulation is associated with decreased PTH-stimulated cAMP accumulation [12, 13] and a blunted phosphaturic response to PTH [13]. Beta-adrenergic activity has also been shown to play a role in the renal handling of phosphate. In particular, respiratory alkalosis producing hypocapnia activates the $\beta$-adrenergic system [21, 22] and attenuates the phosphaturic effect of PTH $[9,10]$. Given these facts, renal sympathetic nerves are one of the most influential factors in increasing renal phosphate reabsorption by inhibiting the phosphaturic response to PTH. We, therefore, 
Table 2. Effect of renal denervation on arterial blood gas analysis results in endotoxemic rats

\begin{tabular}{|c|c|c|c|c|c|c|c|c|c|c|c|c|}
\hline & \multicolumn{4}{|c|}{ Et-treated } & \multicolumn{4}{|c|}{ Saline-treated } & \multicolumn{4}{|c|}{$P$ values (two-way ANOVA) } \\
\hline & \multicolumn{2}{|c|}{ DNX (10) } & \multicolumn{2}{|c|}{ INN (12) } & \multicolumn{2}{|c|}{ DNX (9) } & \multicolumn{2}{|c|}{ INN (7) } & \multicolumn{2}{|c|}{ C } & \multicolumn{2}{|c|}{ Et/Saline } \\
\hline & C & Et & $\mathrm{C}$ & Et & C & Saline & $\mathrm{C}$ & Saline & $\begin{array}{l}\text { Treat- } \\
\text { ment }\end{array}$ & $\begin{array}{c}\text { Renal } \\
\text { nerves }\end{array}$ & $\begin{array}{c}\text { Treat- } \\
\text { ment }\end{array}$ & $\begin{array}{c}\text { Renal } \\
\text { nerves }\end{array}$ \\
\hline $\mathrm{pH}$ & $7.43 \pm 0.02$ & $7.47 \pm 0.03$ & $7.46 \pm 0.03$ & $7.43 \pm 0.04$ & $7.37 \pm 0.02$ & $7.31 \pm 0.02^{\S}$ & $7.42 \pm 0.03$ & $7.35 \pm 0.02^{\S}$ & 0.0427 & 0.0446 & 0.0003 & 0.9718 \\
\hline $\mathrm{PaCO}_{2}(\mathrm{mmHg})$ & $41.0 \pm 3.5$ & $31.2 \pm 3.9^{\S}$ & $38.4 \pm 3.7$ & $32.4 \pm 3.6^{\S}$ & $46.6 \pm 2.6$ & $55.4 \pm 3.2^{\S}$ & $41.5 \pm 3.5$ & $49.3 \pm 2.6$ & 0.0853 & 0.1360 & 0.0001 & 0.4875 \\
\hline $\mathrm{PaO}_{2}(\mathrm{mmHg})$ & $80 \pm 4$ & $91 \pm 8^{\S}$ & $104 \pm 6$ & $103 \pm 6$ & $99 \pm 4$ & $85 \pm 1^{\S}$ & $115 \pm 8$ & $107 \pm 4$ & 0.0188 & 0.0002 & 0.8967 & 0.0042 \\
\hline $\mathrm{HCO}_{3}(\mathrm{mEq} / \mathrm{l})$ & $26.6 \pm 0.9$ & $21.4 \pm 1.3^{\S}$ & $26.1 \pm 0.8$ & $20.3 \pm 0.9^{\S}$ & $26.6 \pm 0.7$ & $27.5 \pm 0.6$ & $26.0 \pm 0.8$ & $26.7 \pm 1.0$ & 0.7395 & 0.3521 & 0.0001 & 0.3845 \\
\hline $\mathrm{BE}(\mathrm{mEq} / l)$ & $2.4 \pm 0.6$ & $-2.0 \pm 1.0^{\S}$ & $2.2 \pm 0.5$ & $-3.7 \pm 0.9^{\S}$ & $1.5 \pm 0.6$ & $1.6 \pm 0.5$ & $1.6 \pm 0.7$ & $1.4 \pm 1.0$ & 0.4606 & 0.9271 & 0.0001 & 0.3402 \\
\hline
\end{tabular}

All values are the means \pm SEM. Numbers in parentheses are the numbers of animals used. Et-treated, endotoxin-injected rats; Saline-treated, saline-injected rats; DNX, rats with denervated kidneys; INN, rats with innervated kidneys; C, control clearance period; $\mathrm{Et}$, clearance period after endotoxin challenge; Saline, clearance period after saline treatment; $\mathrm{pH}$, arterial $\mathrm{pH} ; \mathrm{PaCO}_{2}$, arterial partial pressure of $\mathrm{CO}_{2} ; \mathrm{PaO}_{2}$, arterial partial pressure of $\mathrm{O}_{2} ; \mathrm{HCO}_{3}$, arterial bicarbonate ion concentration; $\mathrm{BE}$, arterial base excess. Treatment, treatment effect of Et or saline injection; Renal nerves, renal nerve effect of DNX or INN; ${ }^{\S}$ significantly different from the control clearance period values, $P<0.05$, paired $t$-test.

hypothesized that removal of the renal sympathetic nerves would normalize the hypophosphaturia. Contrary to our expectations, DNX did not increase phosphate excretion to the same level as in salinetreated rats. Recently Berndt et al. [23] reported that the presence of intact prostaglandin synthesis is vital for the full expression of the phosphaturic effect of PTH in DNX rats under phosphatedepleted conditions where $\beta$-adrenergic activities are greatly enhanced, but it is unlikely that the possibility that decreased prostaglandin $\mathrm{I}_{2}$ synthesis is responsible for the hypophosphaturia during endotoxemia, since renal prostaglandin $I_{2}$ production during endotoxemia has been reported to not decrease [24, 25].

There are two other possible etiologies to explain hypophosphaturia during endotoxemia, hyponatriuresis and metabolic acidosis. We will discuss hyponatriuresis first. Since phosphate transport is secondary to the transcellular sodium gradient, which is provided by the active extrusion of sodium across the basolateral membrane by $\mathrm{Na}^{+}-$ $\mathrm{K}^{+}$ATPase, it is possible that the hypophosphaturia observed in INN and DNX rats was secondary to hyponatriuresis during acute endotoxemia. In the present study, the renal DNX restored the decreased GFRs of endotoxemic INN rats to the level of saline-treated rats, suggesting that the renal nerves play an important role in the pathophysiology of Et-induced acute renal failure. In fact, it has been suggested that renal nerves alter renal hemodynamics by contributing to increased renal vasoconstriction [26, 27], decreased renal blood flow $[28,29]$ and increased renal sodium reabsorption [30,31]. The hyponatriuresis in endotoxemic rats, which was not improved by renal DNX, was due to the diminished renal filtered load of sodium, because the renal reabsorption of sodium per filtered load was similar in Et- and saline-treated rats. Accordingly, it is unlikely that renal DNX would increase the reduced GFR during endotoxemia to the level required to increase the filtered load of sodium.

In the present study, we observed marked hypocapnia in Et-treated rats. Based on negative arterial base excess data and lower bicarbonate ion concentrations, the hypocapnia in the endotoxemic rats was presumably due to compensation for metabolic acidosis, or hypermetabolism. Respiratory alkalosis leading to hypocapnia and acute metabolic acidosis have been reported to inhibit the phosphaturic effect of PTH $[9,10]$ by decreasing PTH-stimulated cAMP formation [11].

In conclusion, (1) renal DNX improved the reduced GFRs during endotoxemia to the normal levels and (2) Et administration resulted in hypophosphaturia, which was not restored to control levels by renal DNX. We failed to obtain the data to support our hypothesis that enhanced renal nerve activity is responsible for hypophosphaturia during acute endotoxemia. 


\section{Acknowledgement}

We wish to thank Drs. Mitsuru Yamakawa, Jun
Maeda, Toshihisa Ogawa, Hajime Kanauchi, Hajime Yamada, Takuro Nakamura, Keizo Uno and Jun-ichi Kojima for their help with this work.

\section{References}

1. Brazy PC, Mandel LJ, Gullans SR, Soltoff SP (1984) Interactions between phosphate and oxidative metabolism in proximal renal tubules. Am J Physiol 247: F575-F581.

2. Gullans SR, Brazy PC, Soltoff SP, Dennis VW, Mandel LJ (1982) Metabolic inhibitors: Effects on metabolism and transport in the proximal tubule. Am J Physiol 243: F133-F140.

3. Rose IA, Warms JVB, O'Connell EL (1964) Role of inorganic phosphate in stimulating glucose utilization of human red blood cells. Biochem Biophys Res Commun 15: 33-37.

4. Rapoport S, Guest GM (1938) Changes of organic acid-soluble phosphorus, diphosphoglycerate, adenosine triphosphate and inorganic phosphorus in the blood cells of rats during the development and healing of rickets. J Biol Chem 126: 749-761.

5. Berkelhammer C, Bear RA (1984) A clinical approach to common electrolyte problems: 3 . hypophosphatemia. Can Med Assoc J 130: 17-23.

6. Mimura $Y$, Yamakawa M, Furuya $K$, Oohara $T$ (1990) Effects of oxygen supply on protein metabolism in surgically injured rats: Oxygen as a nutrient. Ann Surg 212: 228-233.

7. Mimura Y, Uno K, Nakamura T (1997) Renal regulation of phosphate excretion in endotoxemic rats. Clin Exp Pharmacol Physiol 24: 353-358.

8. Constable PD, Schmall LM,Muir III WW, Hoffsis GF (1991) Respiratory, renal, hematologic, and serum biochemical effects of hypertonic saline solution in endotoxemic calves. Am J Vet Res 52: 990-998.

9. Hoppe A, Rybczynska A, Knox FG, Angielski S (1988) $\beta$-Receptors in resistance to phosphaturic effect of PTH in respiratory alkalosis. Am J Physiol 255: R557-R562.

10. Mimura Y, Knox FG (1994) Effect of acute hypoxia on phosphate excretion in rats. Am J Physiol 266: R578-R583.

11. Bellorin-Font E, Humpierres J, Weisinger JR, Milanes CL, Sylva V, Paz-Martinez V (1985) Effect of metabolic acidosis on the $\mathrm{PTH}$ receptor-adenylate cyclase system of canine kidney. Am J Physiol 249: F566-F572.

12. Woodcock EA,Johnston CI (1985) Renal proximal tubular alpha-adrenergic receptors oppose urinary 3, 5'-cyclic adenosine monophosphate response to parathyroid hormone in vivo. Endocrinology 116: 1085-1089.

13. Isaac J, Berndt TJ, Knox FG (1992) Stimulation of alpha2-adrenoreceptors blunts the phosphaturic response to parathyroid hormone. J Lab Clin Med 120: 305-309.

14. LeClaire M, Berndt TJ, Knox FG (1992) Isoproterenol infusion increases the maximal tubular capacity of phosphate reabsorption. Renal Physiol Bioche 15: 134140.

15. Norman RA Jr, Murphy WR, Dzielak DJ, Khraibi AA, Carroll RG (1984) Role of the renal nerves in one-kidney, one clip hypertension in rats. Hypertension Dallas 6: 622-626.

16. Führ J, Kaczmarczyk J, Krüttgen CD (1995) Eine einfache colorimetrishe Methode zur Inulinbestimming für Nieren-ClearanceUntersuchungen bei Stoffwechselgesunden und Diabetikern. Klin Wochenschr 33: 729-730.

17. Bolton WK, Atuk NO (1978) Study of chemical sympathectomy in endotoxin-induced lethality and fibrin deposition. Kidney Int 13: 263-270.

18. Zhou ZZ, Wurster RD, Jones SB (1992) Arterial baroreflexes are not essential in mediating sympathoadrenal activation in conscious endotoxic rats. J Auton Nerv Syst 39: 1-12.

19. MacLean LD, Mulligan WG, McLean APH, Duff JH (1967) Patterns of septic shock in man: A detailed study of 56 patients. Ann Surg 166: 543-562.

20. Shires GT, Canizaro PC (1991) Fluid and electrolyte management of the surgical patient. In: Sabiston DC Jr (ed) Textbook of Surgery: The Biological Basis of Modern Surgical Practice. 14th ed, WB Saunders Company, Philadelphia, 57-76.

21. Brashear RE (1983) Hyperventilation syndrome. Lung 161: 257-273.

22. Folgering H, Cox A (1981) Beta-blocker therapy with metoprolol in the hyperventilation syndrome. Respiration 41: 33-39.

23. Berndt TJ, Khraibi AA, Knox FG (1995) Interaction of the renal nerves and prostaglandins on the phosphaturic response to PTH in phosphatedeprived rats. Am J Physiol 268: R731-R735.

24. Myers SI, Hernandez R, Horton J (1993) Endotoxic shock has differential effects on renal and splanchnic eicosanoid synthesis. Prostaglandins Leukotriences Essen Fatty Acids 49: 509-513. 
25. Badr KF, Kelley VE, Rennke HG, Brenner BM (1986) Roles of thromboxane $\mathrm{A}_{2}$ and leukotrienes in endotoxin-induced acute renal failure. Kidney Int 30: $474-480$.

26. Stella A, Zanchetti A (1985) Interactions between the sympathetic nervous system and the kidney: Experimental observations. J Hypertens 3 (Suppl 4): S19-S25.

27. Kuchel O, Debinski W, Racz K, Buu NT, Garcia R, Cusson JR, Larochelle P, Cantin M, Genest J (1987) An emerging relationship between peripheral sympathetic nervous activity and atrial natriuretic factor. Life Sci 40: 1545-1551.
28. DiBona GF (1986) Neural mechanisms in body fluid homeostasis. Federation Proc 45: 2871-2877.

29. Kopp UC, DiBona GF (1987) Neural control volume homeostasis. In: Brenner BM, Stein JH (eds) Body Fluid Homeostasis: Contemporary Issues in Nephrology. Churchill Livingstone, New York, vol. 16: 185-220.

30. Gottschalk, CW (1979) Renal nerves and sodium excretion. Annu Rev Physiol 41: 229-240.

31. DiBona GF (1987) Neural control of renal tubular sodium reabsorption in the dog. Federation Proc 37: 1214-1217. 